\title{
REVIEW
}

\section{Rational fluid management in today's ICU practice}

\author{
Karsten Bartels', Robert H Thiele² and Tong J Gan*1
}

\begin{abstract}
Intravenous fluid therapy has evolved significantly over time. From the initial report of the first intravenous administration of sodium-chloride-based solution to the development of goal-directed fluid therapy using novel dynamic indices, efforts have focused on improving patient outcomes. The goal of this review is to provide a brief overview of current concepts for intravenous fluid administration in the ICU. Results of recently published clinical trials suggesting harmful effects of starch-based solutions on critically ill patients are discussed. Concepts for goal-directed fluid therapy and new modalities for the assessment of fluid status as well as for the prediction of responsiveness to different interventions will continue to emerge. Advances in technology will have to be critically evaluated for their ability to improve outcomes in different clinical scenarios.
\end{abstract}

\section{Historical perspective}

In 1832, following a suggestion by his mentor Dr William Brooke O'Shaugnessy, Dr Thomas Latta reported his physical examination findings after administrating a saline-based solution to a critically ill and dehydrated cholera patient, at a time when blood-letting was still the standard of care for this condition [1]:

Having inserted a tube into the basilic vein, cautiously-anxiously, I watched the effects; ounce after ounce was injected, but no visible change was produced. Still persevering, I thought she began to breathe less laboriously, soon the sharpened features, and sunken eye, and fallen jaw, pale and cold, bearing the manifest impress of death's signet, began to glow with returning animation; the pulse, which had long ceased, returned to the wrist; at first small and quick, by

*Correspondence: tong.gan@dm.duke.edu

'Department of Anesthesiology, Box 3094, Suite 5670B, Duke University Medical Center, Durham, NC 27710, USA

Full list of author information is available at the end of the article degrees it became more and more distinct, fuller, slower, and firmer, and in the short pace of half an hour, when six pints had been injected, she expressed in a firm voice that she was free from all uneasiness, actually became jocular, and fancied all she needed was a little sleep; her extremities were warm and every feature bore the aspect of comfort and health. [2]

This heretical yet highly successful intervention led to the achievement of a succession of important milestones, including the first use of intravenous albumin in 1834 by Dr John Mackintosh and the introduction of Ringer's solution in 1876 by Sidney Ringer [3], which was modified by Dr Alexis Hartmann to include lactate in 1876 [4]. Despite the accumulating evidence supporting the efficacy of intravenous fluid therapy for conditions that, in hindsight, would be labeled as some form of hypovolemia, the widespread use of intravenous fluid therapy would wait three-quarters of a century until the invention of the Rochester plastic needle - a needle-styletted plastic catheter - by the Mayo Clinic anesthesiology resident Dr David Massa in 1950 [5].

\section{Types of fluid}

\section{Crystalloid solutions}

Components of crystalloid solutions include inorganic ions such as sodium, chloride, potassium, magnesium, and calcium, as well as small organic substances such as glucose or lactate [6]. Examples of commonly used crystalloid solutions and their compositions are summarized in Table 1.

Relevant differences between these solutions include the potassium and calcium concentrations (which theoretically may affect their use in renal failure patients as well as their suitability for mixture with citrated blood products), chloride concentrations and strong ion difference (which ultimately affects the acid-base status of the recipient [7]), and cost.

One myth regarding crystalloid selection deserves further assessment - calcium-containing solutions are not absolutely contraindicated in the setting of transfusion. Most studies demonstrating clotting were based on citrate-phosphate-dextrose-adenine preserved packed red blood cells; newer preservatives, such as AS-3, contain less plasma and more citrate, and are much less 
Table 1. Commonly used intravenous crystalloid solutions

\begin{tabular}{|c|c|c|c|c|}
\hline Crystalloid solution & Components (mEq in $1,000 \mathrm{ml}$ ) & $\mathrm{pH}$ & $\begin{array}{l}\text { Osmolarity } \\
\text { (mOsmol/l) }\end{array}$ & $\begin{array}{c}\text { Cost } \\
(\$ / 1,000 \mathrm{ml})\end{array}$ \\
\hline Lactated Ringer's / Hartmann's solution & Sodium 130, chlorine 109, potassium 4, calcium 3, lactate 28 & 6 to 7.5 & 273 & 0.94 \\
\hline Ringer's acetate & $\begin{array}{l}\text { Sodium } 130 \text {, chlorine } 112 \text {, potassium } 5.4 \text {, calcium } 0.9 \text {, } \\
\text { magnesium } 1 \text {, acetate } 27\end{array}$ & 5.1 to 5.9 & 276 & a \\
\hline Normal saline & Sodium 154, chlorine 154 & 4.5 to 7 & 308 & 1.03 \\
\hline NormoSol-R, Plasma-Lyte A & $\begin{array}{l}\text { Sodium } 140 \text {, chlorine } 98 \text {, potassium } 5 \text {, magnesium } 3 \text {, } \\
\text { acetate } 27 \text {, gluconate } 23\end{array}$ & $\begin{array}{l}\quad 7.4 \text { (other pH } \\
\text { formulations available) }\end{array}$ & 295 & 2.21 \\
\hline $\begin{array}{l}\text { Dextrose } 5 \% \text {, (variable concentrations } \\
\text { available) }\end{array}$ & $\mathrm{H}_{2} \mathrm{O}$, dextrose & 3.2 to 6.5 & 252 & 0.96 \\
\hline
\end{tabular}

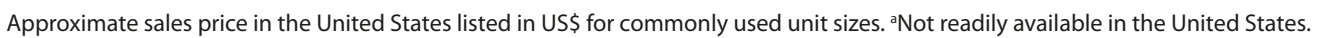

likely to be overwhelmed by the small amount of calcium present in isotonic crystalloids [8].

\section{Colloid solutions}

Colloid solutions consist of homogeneous, noncrystalline large molecules or ultramicroscopic particles (the internal phase) dispersed throughout another substance (the dispersion medium). Colloid solutions can be categorized as blood-derived, such as albumin, plasma protein fraction, and fresh frozen plasma, or as semisynthetic (hydroxyethylstarch (HES), dextrans, and gelatins) [6], several of which are described in Table 2. Base solutions for colloid preparations include normal and hypertonic saline, isotonic glucose, as well as other balanced solutions such as Ringer's lactate or Ringer's acetate.

The primary rationale for administering colloid solution in the setting of hypovolemia is the desire to expand plasma volume more effectively and extend the treatment duration. The larger solutes present in colloidal solutions are theoretically resistant to passage across the capillary membrane, and hence preserve intravascular oncotic pressure and prevent extravasation in accordance with the Starling equation. While this may work in theory, randomized controlled human trials comparing crystalloids with colloids suggest that the volumetric equivalence of colloids to crystalloids is not 1:3, as is classically taught, but somewhere between 1:1.3 and 1:2.1 [9].

\section{Colloid versus crystalloid}

\section{In vitro and animal studies}

Resuscitation of critically ill patients with colloid solutions has been suggested to improve oxygen delivery to the tissues. Initial evidence stems from a small experimental study in a rodent sepsis model, where resuscitation with HES $(130 \mathrm{kDa})$ led to decreased leukocyte adhesion and a better maintained capillary integrity, as measured by macromolecular leakage, when compared with normal saline [10]. In an in vitro study into the effects of $25 \%$ albumin versus $6 \%$ HES $(670 \mathrm{kDa})$ on endothelial inflammation, however, albumin seemed to show a modestly favorable profile as compared with HES [11].

In a sheep study of endotoxin-induced septic shock, resuscitation with larger molecular weight starch (HES 200/0.5) was found to cause a greater decrease in renal function and a higher degree of tubular disruption than therapy with HES 130/0.4 or crystalloid (Sterofundin ${ }^{\circ}$ ISO, B. Braun Melsungen, Germany) [12]. Since the study lasted only 12 hours, acute kidney disease could probably have worsened over time in either group. Deposition of HES into hepatocytes has been reported in patients with worsening hepatic dysfunction [13]. Although the complete mechanism for HES-associated renal dysfunction remains to be discovered, recent in vitro data suggest deposition of HES as vesicle-like structures into proximal tubular cells, as well as decreased cell culture survival with HES compared with incubation with crystalloids [14].

\section{Clinical studies}

\section{Mortality in critically ill patients}

The clinical relevance of the theoretical advantages of colloids (with regards to effects on the microvasculature) was questioned as early as the late 1970s [15]. Clinicians would have to wait almost 30 years, until the completion of the landmark Saline versus Albumin Fluid Evaluation (SAFE) trial, to begin to draw definitive conclusions. The SAFE trial compared the effects of $4 \%$ albumin versus normal saline in 6,997 critically ill patients [16] and found no difference in the primary outcome (all-cause mortality at 28 days). Subgroup analysis revealed a possible association between the use of albumin and increased mortality in patients with traumatic brain injury. It should be noted that this post hoc analysis was performed on only 492 patients or $7 \%$ of the original study population. In a follow-up report of 460 traumatic brain injury patients from the original SAFE trial, the association of albumin with higher mortality rates in this group persisted at 2 years following randomization [17].

The quality and power of previous trials on the safety of low molecular weight starches was questioned in a 
Table 2. Commonly used intravenous crystalloid solutions

\begin{tabular}{|c|c|c|c|}
\hline Colloid solution & Components (per liter) & Source & Cost (\$) \\
\hline Albumin $25 \%$ & $12.5 \mathrm{~g} / 50 \mathrm{ml}$ human albumin & Human & $46.42 / 50 \mathrm{ml}$ \\
\hline Plasma protein fraction $5 \%$ & $\begin{array}{l}50 \mathrm{~g} / \mathrm{l} \text { selected plasma proteins ( } 88 \% \text { albumin, } 12 \% \text { a-globulins } \\
\text { and } \beta \text {-globulins, } 1 \% \text { r-globulins), sodium } 154 \mathrm{mEq} \text {, } \\
\text { potassium } 0.25 \mathrm{mEq} \text {, chlorine } 100 \mathrm{mEq}\end{array}$ & Human & $39.31 / 250 \mathrm{~m}$ \\
\hline Hydroxyethylstarch 130/0.4 & $\begin{array}{l}\text { Hydroxyethylstarch } 130 / 0.4,6 \% \text { in } 500 \mathrm{ml} \text { normal saline } \\
\text { (other base solutions available) }\end{array}$ & Synthesized from amylopectin & $47.13 / 500 \mathrm{~m}$ \\
\hline Hydroxyethylstarch 600/0.75 & $\begin{array}{l}\text { Hydroxyethylstarch } 600 / 0.75,6 \% \text { in } 500 \mathrm{ml} \text { normal saline } \\
\text { (other base solutions are available) }\end{array}$ & Synthesized from amylopectin & $15.55 / 500 \mathrm{~m}$ \\
\hline Gelatin 4\% & $40 \mathrm{~g}$ gelatinpolysuccinate & Bovine collagen & a \\
\hline Dextran 40 & $10 \mathrm{~g}$ dextran $40,5 \mathrm{~g}$ dextrose & $\begin{array}{l}\text { Biosynthesized from sucrose } \\
\text { by Leuconostoc bacteria }\end{array}$ & $20.55 / 500 \mathrm{~m}$ \\
\hline
\end{tabular}

Approximate sales price in the United States listed in US\$ for commonly used unit sizes. ${ }^{\text {Not }}$ readily available in the United States.

meta-analysis of 36 clinical studies (11 of which had previously been retracted) [18]. The more recent Scandinavian 6S trial compared low molecular HES $(130 / 0.42)$ in a Ringer's acetate dispersion medium with Ringer's acetate without starch in the resuscitation of 804 septic ICU patients. This multicenter, randomized, and blinded clinical trial reported that use of up to $33 \mathrm{ml} / \mathrm{kg}$ of $6 \%$ HES (130/0.42) had a significantly higher risk of reaching the primary outcome, defined as death or need for renal replacement therapy at 90 days following randomization, in $51 \%$ of enrolled patients compared with $43 \%$ of enrolled patients receiving Ringer's acetate [19]. As only one patient in each group was receiving renal replacement therapy at 90 days, HES 130/42 increased the absolute risk of death at 90 days by 8 percentage points. Rates of severe bleeding were numerically higher in the HES group compared with crystalloid ( $10 \%$ vs. $6 \%)$, although this did not reach statistical significance $(P=0.09)$.

The Crystalloid versus Hydroxyethyl Starch Trial compared the blinded administration of up to $50 \mathrm{ml} / \mathrm{kg}$ body weight/day HES (130/0.4, Voluven; Fresenius Kabi AG, Bad Homburg, Germany) in normal saline versus normal saline alone in adult patients requiring fluid resuscitation following admission to an ICU [20]. The primary endpoint of all-cause mortality at 90 days was $17 \%$ in the normal saline group and $18 \%$ in the HES group. This difference did not reach statistical significance. Analysis of secondary endpoints revealed an association between HES use and acute kidney injury and a $21 \%$ relative risk increase for renal replacement therapy. Hepatic failure as well as increased use of blood products was also more common in the HES group, although a mild volumesparing effect $(90 \mathrm{ml}$ and $246 \mathrm{ml}$ difference in the volumes of study and nonstudy fluid, respectively, during first 4 days in ICU) was observed. In summary, HES (130/0.4) did not provide any substantial advantages to ICU patients requiring intravenous fluid resuscitation and the analysis of secondary endpoints confirmed an association of its use with renal injury.

\section{Acute kidney injury}

Increasing degrees of oncocity in colloid solutions have been implicated in the incidence of acute kidney disease in a prospective nonrandomized cohort study of 1,013 ICU patients with shock. Both hyperoncotic semisynthetic colloids and hyperoncotic albumin were associated with increased incidences of renal events as compared with crystalloid solutions [21]. A prospective, nonrandomized, cohort study of 346 patients who received HES, gelatin, or crystalloids for fluid resuscitation in the setting of sepsis showed acute kidney injury rates of $70 \%$, $68 \%$, and $47 \%$, respectively [22]. In a retrospective study of 563 cardiac surgery patients, an independent association between the administered dose of Pentastarch $(250 \mathrm{kDa})$ and the development of acute kidney disease was made [23].

The clinical association of both high and low molecular weight starches with renal dysfunction has been confirmed in multiple clinical trials. In the randomized multicenter Volume Substitution and Insulin Therapy in Severe Sepsis trial, HES administration was associated with higher rates of acute kidney disease and renal replacement therapy than was administration of lactated Ringer's solution [24]. However, this was not the primary outcome of this trial. Most recently, the results of the Scandinavian 6S trial were made available: while the number of patients receiving renal replacement therapy at 90 days was no different, patients who were randomized to colloids were significantly more likely to require renal replacement therapy during their hospitalization $(P=0.04)[25]$.

\section{Hemodynamic differences and bleeding risk}

Hartog's assertion that the hemodynamic advantages of colloids are overstated [9] has been supported by more 
recent data. In a randomized clinical trial of 196 sepsis patients receiving resuscitation, comparing HES 130/0.4 with normal saline, HES reduced the volume to reach hemodynamic stability only from 1.709 to 1.379 liters, but it had no effect on the cumulative fluid balance while in the ICU [26]. The assessment of safety profiles of currently used HES formulations had to be critically reevaluated, following the discovery of fraudulent research that possibly favored their use $[27,28]$. The association of HES and postoperative bleeding is well established. A decrease in factor VIII and von Willebrand factor have been linked to the older, large-molecular HES formulations [29] and similarly increased bleeding has been noted following cardiac surgery [30].

The current consensus statement of the European Society of Intensive Care Medicine already discourages the use of HES in patients with severe sepsis or acute kidney disease [31]. The results of both the recent Crystalloid versus Hydroxyethyl Starch Trial and the 6Strial will probably result in a more narrow definition of its use in critically ill patients.

\section{Goal-directed fluid therapy}

For decades, attempts at answering the question 'how much fluid do I give?' focused on the amount of fluid given (usually some arbitrary infusion rate with boluses as needed) and neglected the timing of fluid administration. Interpretation of the myriad of available liberal versus restrictive studies is complicated by a complete lack of standardized definitions of liberal and restrictive. In the early 2000s, several landmark papers suggested that there might be a more rational way to manage hemodynamics with fluid administration.

By manipulating hemodynamics using a complex formula designed to achieve specific targets for mean arterial pressure, urine output, and central venous oxygen saturation in septic patients, Rivers and colleagues showed that mortality could be improved by expanding one's hemodynamic goals beyond simply maintaining adequate blood pressure [32]. One year later, Gan and colleagues showed that a decrease in length of hospital stay and earlier return of bowel function was achieved using a protocol based on optimization of corrected flow time (an esophageal Doppler-derived index of preload) and stroke volume (also derived using esophageal Doppler monitoring) [33].

The clinical value of goal-directed fluid administration has also been demonstrated in other clinical settings and long-term beneficial effects in patients undergoing highrisk procedures have been suggested [34]. Limiting the total amounts of crystalloid infused was associated with decreased complications after major surgery in two groups that were randomized to a low rate or a high rate of crystalloid maintenance [35], suggesting that a fluid restrictive strategy in conjunction with goal-directed therapy might be beneficial. Not all data are supportive. In an earlier study by Gattinoni and colleagues, no difference in mortality in the ICU and at 6 months was detected in 762 critically ill patients randomized to three different hemodynamic goals (normal cardiac index, cardiac index $>4.5 \mathrm{l} / \mathrm{minute} / \mathrm{m}^{2}$, or normal mixed venous oxygen saturation $\geq 70 \%$ ) [36]. A recent trial studying the effects of goal-directed intraoperative fluid therapy using esophageal Doppler monitoring failed to show a beneficial effect and actually found adverse effects in the intervention group. One should note that this study did not show a difference in the amount of fluid (colloid or crystalloid) administered to both groups [37]. Results of a randomized trial investigating mortality in 3,141 children with severe febrile illness and impaired perfusion in subSaharan Africa surprisingly showed higher mortality at 48 hours and at 4 weeks in the group that did not receive any fluid boluses compared with two groups resuscitated with albumin or saline [38]. These results challenge our understanding of the potential benefits of early fluid administration in septic shock and certainly merit further study in other relevant patient groups. However, since this study was performed in a resource-poor environment with limited intensive care and monitoring capabilities, conclusions are probably not directly translatable to clinical practice in other settings.

Overall, it appears that hemodynamic management protocols that focus on either preload or stroke volume optimization, as opposed to maintenance of an arbitrary threshold of blood pressure (or worse, continuous infusion of fluids at an unchanging rate), can improve outcomes. In a meta-analysis of 5,056 surgical patients randomized to tissue-perfusion-based hemodynamic protocols in 32 studies, mortality was reduced (pooled odds ratio $=0.67,95 \%$ confidence interval $=0.55$ to 0.82 ) [39]. Similarly, a meta-analysis in critically ill patients randomized to preemptive hemodynamic management (including 4,805 patients from 29 trials) also found a reduction in mortality (pooled odds ratio $=0.48,95 \%$ confidence interval $=0.33$ to 0.78 ) [40] .

An exciting and relatively new series of hemodynamic endpoints that have firm grounding in cardiorespiratory physiology, but whose impact on clinical outcomes has not been fully discovered, has emerged. Dynamic indices attempt to predict the hemodynamic response to volume administration (that is, change in cardiac output after a standardized fluid bolus) and are based on the interaction between intrathoracic pressure changes and left ventricular end-diastolic volume and cardiac output. These new modalities seem to better answer the question 'what will happen to oxygen delivery if I administer fluids?' [41]. Common variants available in clinical practice include systolic pressure variation, pulse pressure 
variation, stroke volume variation, and the Pleth Variability Index. Systolic pressure variation, pulse pressure variation, and stroke volume variation can be determined via arterial blood pressure tracings. Stroke volume variation can also be obtained from minimally invasive methods, such as esophageal Doppler measurements, and non-invasive cardiac output monitoring using bioreactance technology - but other methods, such as low-frequency oscillations in the plethysmographic waveform (Pleth Variability Index), are also predictive of arterial blood pressure changes induced by mechanical ventilation, and have also been used to successfully predict fluid responsiveness [42]. To determine whether or not these new monitoring technologies will also lead to improved patient outcomes will require appropriately powered clinical trials in the future.

\section{Summary}

Results of multiple smaller clinical trials and recent larger randomized controlled clinical trials advise against the use of both high and low molecular weight starch-based solutions in the care of critically ill patients, because they appear to increase morbidity and rates of renal dysfunction. No convincing data support their impact on improving outcomes. Based on the SAFE trial, albumin and crystalloids appear to have equal effects on mortality in critically ill patients, with the exception of patients with traumatic brain injury.

Goal-directed fluid therapy designed to optimize either stroke volume or preload has been validated in multiple patient groups and has the potential to improve meaningful clinical outcomes. Physicians should resist the blood-pressure-centric approach to hemodynamic management that has, for practical reasons, been the dominant paradigm for over a century, and should make every effort to utilize the currently available technology that can help them give fluids when they are needed, and to restrict them when they are not. Future studies should address both the ideal combination of monitoring devices as well as the choice of fluids in order to develop the best possible treatment strategy for specific clinical scenarios. In particular, stroke volume variation, arterial respiratory variation, and low-frequency oscillations in the photoplethysmographic waveforms are attractive candidate endpoints that need to be further assessed.

A successful fluid management strategy needs to be incorporated into a multimodal interdisciplinary plan of care. We are reminded of this by Dr Latta's humbling closing of his first account of an initially successful resuscitation of a dehydrated cholera patient that fell short on these grounds:

This being my first case, I fancied my patient secure, and from my great need for a little repose, left her in charge of the hospital surgeon; but I had not been long gone, ere the vomiting and purging recurring, soon reduced her to her former state of debility. I was not apprised of the event, and she sunk in five and a half hours after I left her. As she had previously been of sound constitution, I have no doubt the case would have resulted in complete reaction, had the remedy, which already had produced such effect, been repeated. [2]

\section{Key messages}

- HES appears to cause harm and should be avoided in the septic population and in patients at risk for kidney injury.

- The timing of fluid administration is just as important as (if not more important than) the amount given.

- Goal-directed fluid therapy designed to optimize either stroke volume or preload is well established in high-risk patient groups and should be considered in all critically ill patients.

- New modalities for assessment of dynamic indices offer non-invasive options to guide fluid therapy and assess the likely hemodynamic response to volume administration.

\section{Abbreviations}

HES, hydroxyethylstarch; SAFE, Saline versus Albumin Fluid Evaluation.

\section{Competing interests}

TJG has received research fundings from Fresenius Kabi, Inc.

\section{Acknowledgements}

The authors would like to thank Christopher G Murray, PharmD, Gene Rhea, PharmD, and Kuldip Patel, PharmD, for their assistance in estimating the quoted approximate retail prices for fluid solutions.

\section{Author details}

'Department of Anesthesiology, Box 3094, Suite 5670B, Duke University Medical Center, Durham, NC 27710, USA. '2Department of Anesthesiology, University of Virginia School of Medicine, PO Box 800710, Charlottesville, VA 22908-0710, USA.

\section{Declarations}

This article has been published as part of Critical Care Volume 17 Suppl 1, 2013: Future of Critical Care Medicine. The supplement was proposed by Fresenius Kabi based on presentations from the'Future of critical care medicine (FCCM) 2012: Today's practice and a look to the future' symposium. Articles were

commissioned by the journal, were independently prepared by the authors and have been peer reviewed by the journal. Publication of the supplement was supported by Fresenius Kabi.

Published: 12 March 2013

\section{References}

1. Cosnett JE: The origins of intravenous fluid therapy. Lancet 1989, 1:768-771.

2. Latta T: Malignant cholera. Documents communicated by the Central Board of Health, London, relative to the treatment of cholera by the copious injection of aequeus and saline fluids into the veins. The Lancet 1832, 18:274-280.

3. Barsoum N, Kleeman C: Now and then, the history of parenteral fluid administration. Am J Nephrol 2002, 22:284-289.

4. Hartmann AF, Senn MJ: studies in the metabolism of sodium R-lactate. I. Response of normal human subjects to the intravenous injection of sodium R-lactate. J Clin Invest 1932, 11:327-335.

5. Massa DJ, Lundy JS, Faulconer A, Jr, Ridley RW: A plastic needle. Proc Staff 
Meet Mayo Clin 1950, 25:413-415.

6. Grocott MP, Mythen MG, Gan TJ: Perioperative fluid management and clinical outcomes in adults. Anesth Analg 2005, 100:1093-1106.

7. Kellum JA: Determinants of blood pH in health and disease. Crit Care 2000, 4:6-14

8. Albert K, van Vlymen J, James P, Parlow J: Ringer's lactate is compatible with the rapid infusion of AS-3 preserved packed red blood cells. Can J Anaesth 2009, 56:352-356.

9. Hartog CS, Bauer M, Reinhart K: The efficacy and safety of colloid resuscitation in the critically ill. Anesth Analg 2011, 112:156-164.

10. Hoffmann JN, Vollmar B, Laschke MW, Inthorn D, Schildberg FW, Menger MD: Hydroxyethyl starch (130 kD), but not crystalloid volume support, improves microcirculation during normotensive endotoxemia. Anesthesiology 2002, 97:460-470.

11. Lang JD, Jr, Figueroa M, Chumley P, Aslan M, Hurt J, Tarpey MM, Alvarez B, Radi R, Freeman BA: Albumin and hydroxyethyl starch modulate oxidative inflammatory injury to vascular endothelium. Anesthesiology 2004, 100:51-58.

12. Ertmer C, Kohler G, Rehberg S, Morelli A, Lange M, Ellger B, Pinto BB, Rubig E, Erren M, Fischer LG, Van Aken H, Westphal M: Renal effects of saline-based $10 \%$ pentastarch versus $6 \%$ tetrastarch infusion in ovine endotoxemic shock. Anesthesiology 2010, 112:936-947.

13. Christidis C, Mal F, Ramos J, Senejoux A, Callard P, Navarro R, Trinchet JC, Larrey D, Beaugrand M, Guettier C: Worsening of hepatic dysfunction as a consequence of repeated hydroxyethylstarch infusions. J Hepatol 2001, 35:726-732.

14. Neuhaus W, Schick MA, Bruno RR, Schneiker B, Forster CY, Roewer N, Wunde $\mathrm{C}$ : The effects of colloid solutions on renal proximal tubular cells in vitro. Anesth Analg 2012, 114:371-374.

15. Virgilio RW, Rice CL, Smith DE, James DR, Zarins CK, Hobelmann CF, Peters RM: Crystalloid vs. colloid resuscitation: is one better? A randomized clinical study. Surgery 1979, 85:129-139.

16. Finfer S, Bellomo R, Boyce N, French J, Myburgh J, Norton R: A comparison of albumin and saline for fluid resuscitation in the intensive care unit. $N$ Engl $J$ Med 2004, 350:2247-2256.

17. Myburgh J, Cooper DJ, Finfer S, Bellomo R, Norton R, Bishop N, Kai Lo S, Vallance S: Saline or albumin for fluid resuscitation in patients with traumatic brain injury. N Engl J Med 2007, 357:874-884.

18. Gattas DJ, Dan A, Myburgh J, Billot L, Lo S, Finfer S: Fluid resuscitation with $6 \%$ hydroxyethyl starch (130/0.4) in acutely ill patients: an updated systematic review and meta-analysis. Anesth Analg 2012, 114:159-169.

19. Perner A, Haase N, Guttormsen AB, Tenhunen J, Klemenzson G, Aneman A Madsen KR, Moller MH, Elkjaer JM, Poulsen LM, Bendtsen A, Winding R, Steensen M, Berezowicz P, Søe-Jensen P, Bestle M, Strand K, Wiis J, White JO, Thornberg KJ, Quist L, Nielsen J, Andersen LH, Holst LB, Thormar K, Kjældgaard AL, Fabritius ML, Mondrup F, Pott FC, Møller TP, et al: Hydroxyethyl starch 130/0.42 versus Ringer's acetate in severe sepsis. N Engl J Med 2012, 367:124-134.

20. Myburgh JA, Finfer S, Bellomo R, Billot L, Cass A, Gattas D, Glass P, Lipman J, Liu B, McArthur C, McGuinness S, Rajbhandari D, Taylor CB, Webb SA: Hydroxyethyl starch or saline for fluid resuscitation in intensive care. $N$ Engl J Med 2012, 367:1901-1911.

21. Schortgen F, Girou E, Deye N, Brochard L: The risk associated with hyperoncotic colloids in patients with shock. Intensive Care Med 2008, 34:2157-2168

22. Bayer O, Reinhart K, Sakr Y, Kabisch B, Kohl M, Riedemann NC, Bauer M, Settmacher U, Hekmat K, Hartog CS: Renal effects of synthetic colloids and crystalloids in patients with severe sepsis: a prospective sequential comparison. Crit Care Med 2011, 39:1335-1342.

23. Rioux JP, Lessard M, De Bortoli B, Roy P, Albert M, Verdant C, Madore F, Troyanov S: Pentastarch $10 \%(250 \mathrm{kDa} / 0.45)$ is an independent risk factor of acute kidney injury following cardiac surgery. Crit Care Med 2009, 37:1293-1298

24. Brunkhorst FM, Engel C, Bloos F, Meier-Hellmann A, Ragaller M, Weiler N, Moerer O, Gruendling M, Oppert M, Grond S, Olthoff D, Jaschinski U, John S, Rossaint R, Welte T, Schaefer M, Kern P, Kuhnt E, Kiehntopf M, Hartog C, Natanson C, Loeffler M, Reinhart K; German Competence Network Sepsis (SepNet): Intensive insulin therapy and pentastarch resuscitation in severe sepsis. N Engl J Med 2008, 358:125-139.
25. Perner A, Haase N, Guttormsen AB, Tenhunen J, Klemenzson G, Aneman A, Madsen KR, Moller MH, Elkjaer JM, Poulsen LM, Bendtsen A, Winding R, Steensen M, Berezowicz P, Soe-Jensen P, Bestle M, Strand K, Wiis J, White JO, Thornberg KJ, Quist L, Nielsen J, Andersen LH, Holst LB, Thormar K, Kjaeldgaard AL, Fabritius ML, Mondrup F, Pott FC, Moller TP, et al:: Hydroxyethyl starch 130/0.4 versus Ringer's acetate in severe sepsis. N Engl J Med 2012, 367:124-134

26. Guidet B, Martinet O, Boulain T, Philippart F, Poussel JF, Maizel J, Forceville X, Feissel M, Hasselmann M, Heininger A, Van Aken H: Assessment of hemodynamic efficacy and safety of $6 \%$ hydroxyethylstarch $130 / 0.4$ vs. $0.9 \% \mathrm{NaCl}$ fluid replacement in patients with severe sepsis: the CRYSTMAS study. Crit Care 2012, 16:R94.

27. Shafer SL: Shadow of doubt. Anesth Analg 2011, 112:498-500.

28. Reinhart K, Takala J: Hydroxyethyl starches: what do we still know? Anesth Analg 2011, 112:507-511.

29. Kozek-Langenecker SA: Effects of hydroxyethyl starch solutions on hemostasis. Anesthesiology 2005, 103:654-660.

30. Cope JT, Banks D, Mauney MC, Lucktong T, Shockey KS, Kron IL, Tribble CG: Intraoperative hetastarch infusion impairs hemostasis after cardiac operations. Ann Thorac Surg 1997, 63:78-82; discussion 82-83.

31. Reinhart K, Perner A, Sprung CL, Jaeschke R, Schortgen F, Johan Groeneveld $A B$, Beale R, Hartog CS: Consensus statement of the ESICM task force on colloid volume therapy in critically ill patients. Intensive Care Med 2012, 38:368-383.

32. Rivers E, Nguyen B, Havstad S, Ressler J, Muzzin A, Knoblich B, Peterson E, Tomlanovich M: Early goal-directed therapy in the treatment of severe sepsis and septic shock. N Engl J Med 2001, 345:1368-1377.

33. Gan TJ, Soppitt A, Maroof M, el-Moalem H, Robertson KM, Moretti E, Dwane P, Glass PS: Goal-directed intraoperative fluid administration reduces length of hospital stay after major surgery. Anesthesiology 2002, 97:820-826.

34. Rhodes A, Cecconi M, Hamilton M, Poloniecki J, Woods J, Boyd O, Bennett D, Grounds RM: Goal-directed therapy in high-risk surgical patients: a 15-year follow-up study. Intensive Care Med 2010, 36:1327-1332.

35. Lobo SM, Ronchi LS, Oliveira NE, Brandao PG, Froes A, Cunrath GS, Nishiyama KG, Netinho JG, Lobo FR: Restrictive strategy of intraoperative fluid maintenance during optimization of oxygen delivery decreases major complications after high-risk surgery. Crit Care 2011, 15:R226.

36. Gattinoni L, Brazzi L, Pelosi P, Latini R, Tognoni G, Pesenti A, Fumagalli R: A trial of goal-oriented hemodynamic therapy in critically ill patients. $\mathrm{SvO}_{2}$ Collaborative Group. N Engl J Med 1995, 333:1025-1032.

37. Challand C, Struthers R, Sneyd JR, Erasmus PD, Mellor N, Hosie KB, Minto G: Randomized controlled trial of intraoperative goal-directed fluid therapy in aerobically fit and unfit patients having major colorectal surgery. $\mathrm{Br} J$ Anaesth 2012, 108:53-62.

38. Maitland K, Kiguli S, Opoka RO, Engoru C, Olupot-Olupot P, Akech SO, Nyeko R, Mtove G, Reyburn H, Lang T, Brent B, Evans JA, Tibenderana JK, Crawley J, Russell EC, Levin M, Babiker AG, Gibb DM; FEAST Trial Group: Mortality after fluid bolus in African children with severe infection. N Engl J Med 2011, 364:2483-2495.

39. Gurgel ST, do Nascimento P, Jr: Maintaining tissue perfusion in high-risk surgical patients: a systematic review of randomized clinical trials. Anesth Analg 2011, 112:1384-1391.

40. Hamilton MA, Cecconi M, Rhodes A: A systematic review and meta-analysis on the use of preemptive hemodynamic intervention to improve postoperative outcomes in moderate and high-risk surgical patients. Anesth Analg 2011, 112:1392-1402

41. Marik PE, Cavallazzi R, Vasu T, Hirani A: Dynamic changes in arterial waveform derived variables and fluid responsiveness in mechanically ventilated patients: a systematic review of the literature. Crit Care Med 2009, 37:2642-2647.

42. Natalini G, Rosano A, Taranto M, Faggian B, Vittorielli E, Bernardini A: Arterial versus plethysmographic dynamic indices to test responsiveness for testing fluid administration in hypotensive patients: a clinical trial. Anesth Analg 2006, 103:1478-1484.

doi:10.1186/cc11504

Cite this article as: Bartels K, et al:: Rational fluid management in today's ICU practice. Critical Care 2013, 17(Suppl 1):S6. 